\title{
Animal economics: assessing the motivation of female laboratory rabbits to reach a platform, social contact and food
}

\author{
SHIRLEY C. SEAMAN*, NATALIE K. WARAN†, GEORGIA MASON $\ddagger$ RICHARD B. D’EATH§ \\ *Royal (Dick) School of Veterinary Studies, University of Edinburgh \\ $\dagger$ School of Natural Sciences, Unitec New Zealand \\ $\ddagger$ Department of Animal \& Poultry Science, University of Guelph \\ $\S$ Animal Behaviour \& Welfare, Sustainable Livestock Systems, Scottish Agricultural College (SAC) Edinburgh \\ (Received 23 February 2006; initial acceptance 13 April 2006; \\ final acceptance 5 November 2006; published online 19 December 2007; MS. number: 8859)
}

\begin{abstract}
We used novel techniques for assessing resource value to investigate what additions to a barren cage female laboratory rabbits, Oryctolagus cuniculus, value. We tested motivation to reach two resources that are potentially practical enrichments: a platform (providing a partly enclosed space and a raised area) and limited social contact with another rabbit through wire mesh and compared these to food and an empty space. To reach these resources, rabbits had to pay entry costs (pushing through weighted doors) which increased every 2 days. With rising costs, rabbits generally rescheduled their behaviour, often reducing visit number and increasing visit length. Measures from economics and behavioural ecology ranked the relative importance of resources similarly (food $\geq$ social contact $\geq$ platform $>$ empty cage). 'Travel cost consumer surplus' (the area under a demand curve of price versus number of visits) ranked food and social contact similarly, but higher than the platform; 'aggregate consumer surplus' (the area under a plot of weight against the number of rabbits paying each price level for the resource) placed food higher than both social contact and the platform; 'reservation price' (maximum weight pushed) did not discriminate between the three resources; and 'expenditure rate' (weight $\times$ visits/days) again ranked food and social contact similarly, but higher than the platform. Overall, rabbits' motivation for access to limited social contact thus came close to that for food, suggesting that they value this highly. Rabbits were almost as strongly motivated to be near a platform, but rarely used it, suggesting it might serve a 'bolt hole' function.
\end{abstract}

(c) 2007 The Association for the Study of Animal Behaviour. Published by Elsevier Ltd. All rights reserved.

Keywords: access costs; animal economics; consumer demand; laboratory rabbit; motivation; Oryctolagus cuniculus; resource value

Rabbits, Oryctolagus cuniculus, are widely used in research, primarily in medical studies; around 15000 each year in U.K. (Home Office 2004), and over 260000 in Europe (European Commission 2005). Changing their housing and husbandry to improve welfare is thus valuable. Recently, concerns have been raised that barren cages not

Correspondence: S. C. Seaman, Veterinary Clinical Sciences, Royal (Dick) School of Veterinary Studies, University of Edinburgh, Easter Bush Veterinary Centre, Roslin, Midlothian EH25 9RG, U.K. (email: shirley.seaman@ed.ac.uk).N.K. Waran is at the School of Natural Sciences, Unitec New Zealand, Private Bag 92025, Carrington Road, Mt Albert, Auckland, New Zealand. G. Mason is at the Department of Animal \& Poultry Science, University of Guelph, Guelph, Ontario N1G 2W1, Canada. R. B. D'Eath is at SAC, Kings Buildings, West Mains Road, Edinburgh EH9 3JG, U.K. only lead to poor welfare, but also render the laboratory animals poor subjects in some scientific experiments (Würbel 2001; Jain \& Baldwin 2003; Sherwin 2004a). How best to improve such cages was our broad aim in this study.

Pair or social housing of female rabbits is recommended where possible (Home Office 1989; Morton et al. 1993). Rabbits are naturally social (Cowan \& Bell 1986), with domestic rabbits retaining the social behaviour repertoire of their wild ancestors (Stodart \& Myers 1964). Pair or social housing for female laboratory rabbits reduces abnormal behaviour (Whary et al. 1993; Gunn \& Morton 1995; Chu et al. 2004), and rabbits may also prefer it to single housing: pair-housed rabbits spend most (88\%) of their time close together (Huls et al. 1991). Unfortunately, pair or social housing of female rabbits is not always possible. A recent survey of U.K. pharmaceutical companies 
(Seaman 2002) found that single housing of females was relatively common ( $46 \%$ of rabbits) since it was deemed necessary for certain experiments (Morton et al. 1993; Seaman 2002). Some manufacturers are therefore now providing cages that maintain individual housing, while allowing limited social contact between adjacent rabbits through a grill or clear Perspex. It is not known whether such limited social contact is attractive to rabbits, and assessing this was one goal of the present study.

Enclosed or partly enclosed boxes or shelves may provide another form of enrichment by providing a raised platform and an enclosed 'burrow-like' retreat underneath. Wild rabbits regularly sit on their hindlegs and/or use natural rises for vigilance (Batchelor 1991; Gibb 1993); they also use burrows, bolt holes and vegetation to provide cover from predators (e.g. Kolb 1991). Laboratory rabbits similarly climb on raised areas, apparently for vigilance, exploration or to rest (Whary et al. 1993; Hansen \& Berthelsen 2000). Platforms are now provided by some cage manufacturers, and information on rabbits' motivation to have access to platforms is another aspect of the present study.

To determine whether a change to the housing environment leads to improved welfare, a number of approaches are useful. These include observation of the changes in physiology or behaviour, for instance as described above (e.g. Hansen \& Berthelsen 2000), and the measurement of an animal's motivation to use the added resources. To do this, costs can be imposed on resource use to assess the extent to which use is defended (Dawkins 1983, 1990; Kilgour et al. 1991; Fraser \& Matthews 1997; Mason et al. 2001; Kirkden \& Pajor 2006). Costs may be applied prior to resource access, such as increasing ratio schedules for an operant task such as lever pressing (Hursh et al. 1988; Sherwin \& Nicol 1997), or overcoming an obstacle such as a narrow gap (Cooper \& Appleby 1996) or weighted door (Mason et al. 2001; Olsson \& Keeling 2002). Alternatively, costs may be applied continually during resource use (Johnson \& Cabanac 1982; Faure \& Lagadic 1994). It is important that the tested resources are available to the animal only within the test environment (a 'closed economy'); otherwise animals may refuse to pay the costs while under test, and obtain the resources for free once the test is over (Houston \& McNamara 1989; Mason et al. 1998; Ladewig et al. 2002). This type of approach for assessing animals' priorities is now widely used in animal welfare research, but potentially has more general applicability, for instance in studies of foraging, mate choice, parental investment and the circadian scheduling of activities.

Various measures from human economics (e.g. Varian 1993; Begg et al. 2003) can be used to interpret how changes in behaviour with increasing cost relate to the importance of the resource to the animal. Welfare researchers have typically focused on one measure known as the price elasticity of demand (e.g. Dawkins 1983, 1990; Matthews \& Ladewig 1994; Gunnarsson et al. 2000). Put simply, if consumption drops with rising cost, demand is said to be 'elastic', while 'inelastic' demand occurs when consumption is defended despite rising cost. However, this measure has several inherent problems (Kirkden \& Pajor
2006), including that it can be confounded by satiation (Kirkden et al. 2003; Kirkden \& Pajor 2006), that resources that take a greater proportion of the subject's budget tend to be more elastic (e.g. Sloman 1999; Warburton \& Mason 2003; Sorensen et al. 2004), and that human economists thus do not use elasticity to assess resource value. Furthermore, to measure price elasticity of demand, there must be a fixed relation between the unit of cost paid and the unit of reward delivered (e.g. Mason et al. 1998), such as a fixed amount of food or water (Hursh et al. 1988) or a fixed period of access to a resource (Gunnarsson et al. 2000). However, if the resource unit is made too small (e.g. access periods are too short), this may devalue certain types of resource (e.g. those that allow sleeping/resting, Jensen et al. 2005; Munksgaard et al. 2005), and it has therefore been argued that animals should be allowed to schedule their own bouts of behaviour (Mason et al. 1998). This was the type of set-up we wanted, but in some variants of this, for example where animals pay a cost on access but can then stay as long as they choose, the price paid and the amount consumed no longer covary (Mason et al. 1998), making it impossible to calculate elasticity meaningfully even if one wanted to.

For all these reasons, we preferred measures other than elasticity of demand. Consumer surplus measures the area under the demand curve of access price versus the amount consumed, and it is used in economics to estimate the value of a resource to human consumers (Ng 1990; Houston 1997; Kirkden et al. 2003). Environmental economists (e.g. Hanley et al. 1997) use a variant called the 'travel cost consumer surplus' to value nonmarket goods such as areas of natural beauty: this is the area under a demand curve of visit price (e.g. journey cost) versus number of visits. 'Aggregate consumer surplus' is the area under an aggregate plot of price versus the number of subjects prepared to pay each price (e.g. Varian 1993). Reservation price is used by economists (e.g. Varian 1993) to refer to the maximum price the consumer is willing to pay for a particular resource (Manser et al. 1996; Mason et al. 2001; Olsson \& Keeling 2002; Warburton \& Mason 2003; see also Kirkden et al. 2003). This can be thought of as the consumer surplus for the first unit of a resource after a period without (Kirkden et al. 2003). This measure has some advantages: it is one of the few economic measures that, for humans, ranks the value of water above that of diamonds (Begg et al. 2003, page 71), suggesting good validity for welfare work; and it also seems to remain similar whether or not incentive cues from the resources are present (Warburton \& Mason 2003), perhaps being most driven by the buildup of internal motivation during deprivation. Finally, we also used expenditure rate (visits $\times$ weight/days), i.e. the average expenditure each day on each resource (Warburton \& Mason 2003); this measure is loosely derived from optimal foraging theory, and assumes that as expenditure rate increases, the benefit to the animal must also increase (but for critique see Kirkden \& Pajor 2006).

Our focus of interest was the motivation of laboratory rabbits to reach limited social contact and a platform. For context, two further resources were provided: food and an empty cage. Use of food as a comparator can be valuable (Dawkins 1983, 1990; Warburton \& Mason 2003) since 
access to food is clearly vital for animal welfare. The empty cage was included because animals may be prepared to pay costs to have access to empty spaces per se (Sherwin \& Nicol 1997; Sherwin 2004b), perhaps motivated by territory inspection or patrolling (Cowan 1977). Each resource cage provided both extra space and patrolling opportunities, additional to the resources they contained, so the empty cage helped control for these aspects.

\section{METHODS}

\section{Subjects, Housing and Husbandry}

The subjects were 12 female New Zealand White rabbits, obtained from a commercial breeder at 13 weeks of age, where they had been kept as part of a larger social group in a floor pen. This breed is by far the most commonly used in laboratories in the U.K. (Batchelor 1999; Seaman 2002). One rabbit had to be removed from the experiment in the early stages because of a false pregnancy.

From the day they were obtained until 6-12 weeks before the experiment started, the rabbits were singly housed in standard laboratory rabbit cages (Tecniplast S.P.A., Buguggiate (Va), Italy; $0.77 \times 0.70 \mathrm{~m}$ and $0.5 \mathrm{~m}$ high). These were held in two racks, which each held six cages in three tiers of two. No visual or tactile contact between rabbits was possible, although sound and olfactory cues were available. The rabbits had ad libitum access to commercial rabbit pellets (STANRAB (P), Special Diet
Services, Witham, Essex, U.K.) in a metal hopper, hay placed on the floor and water from a drinking bottle. The cages had plastic floors with circular perforations which allowed urine and faeces to fall through on to a litter tray beneath (cleaned every 2-3 days). The rabbits were provided with wooden blocks and cardboard tubes to gnaw on and manipulate (Huls et al. 1991; Morton et al. 1993), along with small plastic mesh balls containing hay, re-filled twice weekly, as foraging enrichments (Morton et al. 1993; Lidfors 1997). The light cycle was 10:12 h light:dark, with $1 \mathrm{~h}$ of dim light between the two periods ('dawn' and 'dusk'). At the start of the experiment, the rabbits were 22-27 weeks old and weighed $2.95-3.95 \mathrm{~kg}(\bar{X} \pm \mathrm{SD}=3.5 \pm 0.32 \mathrm{~kg})$.

\section{Apparatus}

Four plus-shaped (+) sets of apparatus were built from wooden sheeting $5 \mathrm{~mm}$ thick (Fig. 1). The central area of the apparatus $(0.71 \times 0.55 \mathrm{~m}$ and $0.61 \mathrm{~m}$ high $)$ contained a water bottle and was surrounded by four resource cages $(0.71 \times 0.55 \mathrm{~m}$ and $0.61 \mathrm{~m}$ high $)$. Each apparatus had the same perforated plastic floor as the home cages, and was covered above with wire mesh. All were located within the same room, so the test rabbits would have been able to hear and smell, but not see, each other.

Each resource cage could be reached only from the central area through a one-way transparent Perspex pushdoor measuring $0.18 \times 0.19 \mathrm{~m}$ (Cat Mate Large cat flap,

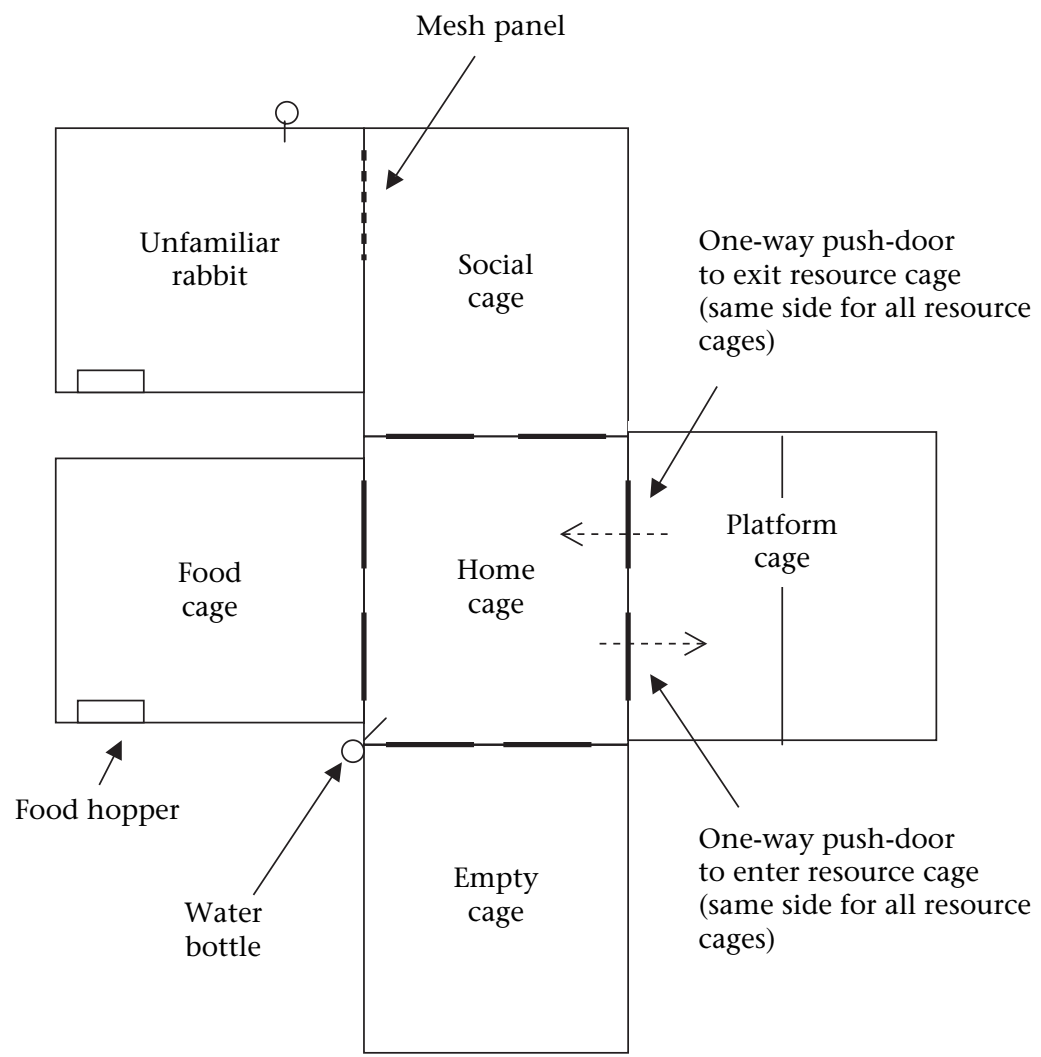

Figure 1. One of the four plus-shaped sets of apparatus showing the resource available in each resource cage. 
Pet Mate Ltd, Hersham, Surrey, U.K.) to which weights could be attached. A second identical door next to each entrance door provided the only exit from the resource cages; this was never weighted. When the weights were attached, the rabbits were unable to see through the entry doors, but they could still see into the resource cages through the exit doors. Each resource cage contained a different resource only available in that location. These were food, limited social contact, a platform and an empty cage. The food cage contained ad libitum pellets in a metal hopper and hay placed on the floor. Rabbits were never seen to remove pellets or hay from this cage. The social contact cage was an otherwise empty cage with a mesh panel $(0.3 \times 0.2 \mathrm{~m}$, mesh size $25 \mathrm{~mm})$ in the side wall allowing visual, olfactory and minimal tactile contact with an unfamiliar female rabbit. This rabbit was housed for the duration of the experiment in a cage $(0.71 \times 0.65 \mathrm{~m}$ and $0.61 \mathrm{~m}$ high) with pellets, hay and water ad libitum, as well as a wooden block, cardboard tube and hay-filled mesh ball. The experimental rabbits were used as the unfamiliar rabbits, with each being used only once, and the same pair never meeting twice (thus if A was the 'stimulus rabbit' for test rabbit $\mathrm{B}$, when $\mathrm{A}$ was the test rabbit, $\mathrm{B}$ was not used as the stimulus rabbit). The platform cage was a slightly larger cage $(0.71 \times 0.64 \mathrm{~m}$ and $0.81 \mathrm{~m}$ high) containing a raised platform $(0.64 \times 0.31 \mathrm{~m}$ and $0.2 \mathrm{~m}$ high) taken from a Tecniplast laboratory rabbit cage. The empty cage provided no resources other than an additional area. The position of the resources relative to the central area was varied between the four sets of apparatus. We carried out the experiment with two groups of four rabbits, and one of three, to which the rabbits were randomly assigned. The apparatus was thoroughly cleaned with Virkon disinfectant (DuPont RelyOn Prevention Solutions, Sudbury, Suffolk, U.K.) between groups.

We videotaped behaviour using cameras (Panasonic WV-BP330/B) mounted above each set of apparatus, a quad unit (Panasonic WJ-410) and a time-lapse video recorder (Panasonic AG-6024). Infrared lights were used during the dark hours of the light cycle. For sampling protocols, see below.

\section{Procedure}

Entrance push-doors were fixed open and one rabbit was placed in the central area of each apparatus. The rabbit was allowed to explore for $1 \mathrm{~h}$ during which time it was remotely observed to ensure that it entered all the areas, after which time the entrance push-doors were closed. The rabbits were then left for 5-7 days to become familiar with the apparatus $(\bar{X} \pm \mathrm{SD}=6.5 \pm 0.7$ days $)$. We used behaviour recorded during the final 2 days of this period of free access in the analysis.

Every morning at 0900 hours the rabbits were removed from the apparatus and placed in their laboratory cage for approximately $1 \mathrm{~h}$ to allow for cleaning and the replacement of food and water. While in their cages the rabbits did not have access to any of the resources from the apparatus. For welfare reasons, each day we weighed the pelleted food left in the food hopper in the apparatus to monitor the rabbits' intake. The rabbits were weighed and given a health check once a week.

After the period of free access, a weight of $0.25 \mathrm{~kg}$ was bolted to each of the entrance push-doors during alternate daily husbandry periods. At $48-\mathrm{h}$ intervals, additional $0.25-\mathrm{kg}$ weights were added to each door. Exit doors remained unweighted.

\section{Ethical Note}

Because of welfare and veterinary concerns about food deprivation, the rabbits were closely monitored to ensure that they continued to enter the food resource cage as each new weight was added. Daily weighing of food consumed suggested that consumption remained constant, and weekly weighing of the rabbits found either no change or an increase in weight. In accordance with Home Office guidelines, and in consultation with the institution's named veterinary surgeon, we ended the experiment for any rabbit that did not obtain food for $20 \mathrm{~h}$. It was then returned to its laboratory cage and immediately provided with ad libitum hay and pellets. Since this was the criterion for the termination of the experiment for an individual, all of the rabbits experienced the $20 \mathrm{~h}$ without access to food on only one occasion. (The implications of this aspect of methodology are considered in the Discussion.)

\section{Behavioural Observations}

A new observation day began after the daily husbandry period, and ended at 0900 hours the following day. On each of the last 2 days without weights, and all subsequent days with weights, we recorded the number of visits the rabbits made to each cage, and the duration of each visit.

Video data on the behaviour of the rabbits in the social contact and platform cages were collected to give an indication of how the rabbits used these resources. To investigate resource use within the social contact and platform cages we had three sampling periods: the last 10 'free access' visits, the first 10 visits at $0.25 \mathrm{~kg}$ and the final 10 visits at the maximum weight. Within each sample, continuous observations were made. For each visit to the social contact cage, we recorded the latency to first approach within $0.05 \mathrm{~m}$ of the mesh panel. The position of the rabbits within the cage was recorded (defined by their head position) as being in the rear half of the cage nearest to the other rabbit, or in the front half nearer to the entrance and exit doors. The time the rabbits spent directly at the mesh panel was also recorded (defined as the time spent oriented towards the mesh with their nose within $0.05 \mathrm{~m}$ of it), as was the time both rabbits were at the mesh panel simultaneously. The behaviour of the rabbits in front of the mesh panel was recorded continuously to characterize the nature of the behaviour displayed at the mesh panel (Table 1). The fact that interactions were occurring across a mesh panel meant that the rabbits were not able to display the typical behaviours that would be seen during social interactions; however, we could categorize the observed behaviours as aggressive, exploratory/marking or nonaggressive. Behaviours categorized 
Table 1. Ethogram of behaviours used to characterize the nature of behaviour at the mesh panel

\begin{tabular}{|c|c|}
\hline Behaviour & Description \\
\hline $\begin{array}{l}\text { Investigating } \\
\text { (Exploratory/marking) }\end{array}$ & $\begin{array}{l}\text { Sniffing or chin marking } \\
\text { mesh panel }\end{array}$ \\
\hline $\begin{array}{l}\text { Standing/sitting } \\
\text { (Nonaggressive) }\end{array}$ & $\begin{array}{l}\text { Standing/sitting directly in } \\
\text { front of mesh panel without } \\
\text { any physical contact }\end{array}$ \\
\hline Rearing (Exploratory) & $\begin{array}{l}\text { Standing on back legs while } \\
\text { in front of mesh panel }\end{array}$ \\
\hline Scratching (Aggressive) & $\begin{array}{l}\text { Using front paws to } \\
\text { scratch at mesh panel }\end{array}$ \\
\hline Lungeing (Aggressive) & $\begin{array}{l}\text { Sudden movement } \\
\text { towards mesh panel }\end{array}$ \\
\hline
\end{tabular}

as aggressive appeared to be thwarted versions of behaviours that would normally be observed during agonistic interactions, such as chasing, biting and scratching (Albonetti et al. 1990; Batchelor 1991). In the platform cage, the rabbits were recorded as being on the platform, under the platform or in front of the platform.

\section{Statistical Analysis}

Data from the last $48 \mathrm{~h}$ of free access and each of the 48$h$ weighted periods were first used to analyse how the number and duration of visits to resource cages were affected as the rabbits rescheduled their behaviour in accordance with the increasing cost of gaining access to the resources (Sherwin \& Nicol 1996; Cooper \& Mason 2000). For each day, we calculated total visit number, mean duration and total duration of visits to each resource cage. Then, for each weight, we calculated means over the 2 days. Because each rabbit's experiment ended when it had failed to obtain food for $20 \mathrm{~h}$, this led to incomplete days which were discarded from the analysis, and data for 1 day at the final weight were sometimes used in the analysis. We then used repeated measures ANOVA (Genstat Release 7.2, VSN International Ltd, Hemel Hempstead, U.K.) to determine how number, total duration and mean duration of visits were affected by resource and cost.

For this analysis, we used data from the unweighted day and up to the fifth weight. Only two rabbits continued to the sixth and seventh weights, so there were too many missing values for these to be included. Rabbit was entered as a block ( $N=11$ rabbits), and resource was entered at the next level of the analysis ( $N=4$ resources) with 30 degrees of freedom of residual error at this level (for the rabbit $\times$ resource combinations). Increasing weight was entered as the repeated measure $(d f=5)$ and the interaction between weight and resource was also fitted at this level $(d f=15)$. When a rabbit made no visits to a resource in a 2-day period (65 occasions), visit number and total duration were zero, and mean visit duration was entered as a missing datum. These zeros in the data set meant that normality of the residuals could not be improved by transformation, and, instead, we used randomization tests to calculate critical values of $F$.
Because repeated measures ANOVA treats the weight data as a series of response variates, rather than as a covariate, it does not calculate regression coefficients which would summarize the direction of effects and interactions in a simple way. To aid interpretation, these were generated using a general linear model (in Minitab, Minitab Inc., State College, PA, U.S.A.), running the model $Y=$ Rabbit identity + Weight + Resource + Weight $\times$ Resource, with weight fitted as a covariate and rabbit as a random factor. This model was then used with each of number of visits, total visit duration and mean visit duration as $Y$. Only the regression coefficients are reported from this analysis.

We determined the following economic measures for each rabbit and each resource: travel cost consumer surplus (kg), aggregate consumers' surplus (kg), reservation price $(\mathrm{kg})$ and expenditure rate $(\mathrm{kg} / \mathrm{day})$. Since the aggregate consumers' surplus produces a single number for each resource from all of the rabbits, no statistical analysis of this measure was possible. For the other measures, we used raw data and residual analysis confirmed that transformations were not necessary to improve normality. Data were analysed with two-way ANOVA (Minitab version 14), fitting resource and rabbit identity (to adjust for differences between individuals). When resource emerged as significant, we used post hoc least-square difference (LSD) tests to identify which resources were significantly different from each other.

Descriptive statistics were used to summarize latency to approach the mesh panel and behaviour within the social cage. To determine whether location in the cage differed between individual rabbits or the three sampling periods, we analysed, with two-way ANOVA (residual histograms were normal), the percentage of time spent in three areas of the cage (within $5 \mathrm{~cm}$ of the mesh panel, the back half of the cage, not including the mesh panel area, and the front of the cage). In addition, we compared time spent in the three areas to the null hypothesis that rabbits spent their time in proportion to the available floor area. Data were not normally distributed, so we used one-sample Wilcoxon tests (Genstat Release 7.2) to test whether the differences were different from zero. We carried out similar analyses for three areas within the platform cage (time spent on, under or in front of the platform). We also used two-way ANOVA to determine whether the latency to approach the mesh panel differed between individual rabbits or the three sampling periods. The differences in weight between the subject and stimulus rabbits were calculated from the weights taken on the first day the rabbits were placed in the apparatus. Using Pearson correlations, we correlated difference in weight with latency to approach the mesh, number of rears and time spent at the mesh, and with the economic measures (travel cost consumer surplus, reservation price and expenditure rate).

\section{RESULTS}

\section{Visit Number and Duration}

There were significant differences between resources in visit number (repeated measures ANOVA: $F_{3,30}=22.0$, 
$P<0.001)$, mean duration $\left(F_{3,30}=27.5, P<0.001\right)$ and total duration of visits $\left(F_{3,30}=8.60, P<0.001\right)$. As predicted, as weights increased, the number of visits to all resources systematically declined $\left(F_{5,200}=129.1, P<0.001\right.$; regression coefficient $\pm \mathrm{SE}=-2.94 \pm 0.15$; Fig. 2), whereas mean visit duration typically, although not always increased $\left(F_{5,135}=68.8, P<0.001\right.$; main effect regression coefficient $\pm \mathrm{SE}=0.014 \pm 0.002$; Fig. 2). Overall, the total time spent with resources typically increased slightly as the first weight was introduced, and remained largely the same before falling at the highest weights $\left(F_{5,200}=8.67\right.$, $P<0.001$; regression coefficient $\pm \mathrm{SE}=-0.015 \pm 0.005$; Fig. 2). However, there were differences in these effects, i.e. use was rescheduled to different extents between different resources, as revealed by significant interactions between resource and weight for all measures. Thus mean visit duration (resource $*$ weight; $F_{15,135}=28.1$, $P<0.001)$ increased more rapidly with increasing weight for the platform than for the other resources (interaction regression coefficients: empty: 0.005; food: -0.009 ; platform: 0.012; social contact: -0.007$)$. Visit number (resource $*$ weight; $F_{15,200}=8.07, P<0.001$ ) declined most rapidly for social contact, followed by food (regression coefficients: empty: 1.77; food: -0.91 ; platform: 0.51 ; social contact: $-1.37)$. The rate of decline in visit number was slowest for the empty cage, as the starting point was fewer visits, although the relative decline appeared to be marked (Fig. 2). Finally, total duration (resource $*$ weight; $\left.F_{15,200}=3.34, P<0.001\right)$ spent with food and social contact stayed almost the same, while time in the empty
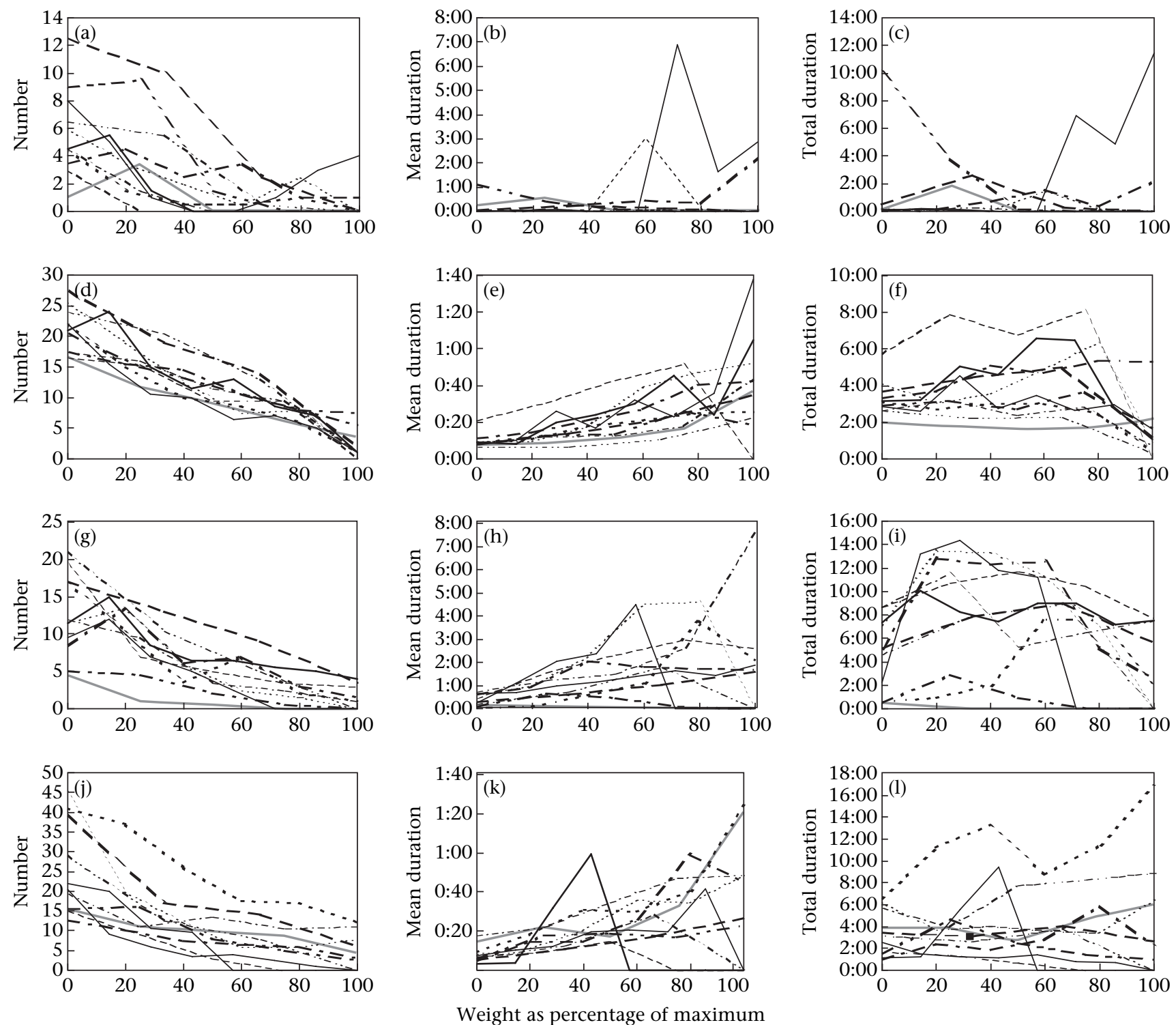

Figure 2. Number of visits, mean visit duration (h:min) and total visit duration (h:min) for each resource against door weight expressed as a percentage of the reservation price for food. $(a-c)$ Empty cage, $(d-f)$ food, $(g-i)$ platform and $(j-l)$ another rabbit (social). Means over the 2 days at each weight are shown for individual rabbits. 
cage generally fell, and total duration with the platform generally increased with the introduction of the first weight and subsequently fell with increasing weight (regression coefficients: empty: 0.010; food: 0.000; platform: -0.018 , social contact: 0.008$)$. However, there were some marked differences in rescheduling patterns between individual rabbits, especially for all three nonfood resources (Fig. 2).

\section{Economic Analyses}

Travel cost consumer surplus (area under the curve of weight against the number of visits as the dependent variable, calculated for each rabbit) tended to differ between rabbits although not significantly so (repeated measures ANOVA: $\left.F_{10,30}=1.83, P=0.098\right)$, and differed significantly between resources $\left(F_{3,30}=19.25, P<0.001\right.$; Fig. 3). LSD tests showed that the empty cage had a lower value than food $(P<0.001)$, social contact $(P<0.001)$ and platform $(P<0.02)$. The platform had a lower value than social contact $(P<0.002)$ and food $(P<0.001)$.

Figure 4 shows the number of rabbits obtaining access to each resource at each weight. The number visiting the empty cage began to decline at lower weights, while the number visiting food was more sustained at high costs than for the other resources. The platform and social contact cages have similar curves, just under that for food. For each resource, the aggregate consumer surplus (the area under these curves in $\mathrm{kg}$ ) was empty 8.3, platform 12.0, social contact 12.1, food 13.6.

Reservation price (maximum weight pushed) differed between rabbits (repeated measures ANOVA: $F_{10,30}=5.39$, $P<0.001)$ and also between resources $\left(F_{3,30}=5.28\right.$, $P=0.005$; Fig. 5). LSD tests showed that the reservation price for the empty cage was lower than those for food $(P<0.001)$, platform $(P<0.02)$ and social contact $(P<0.02)$.

Expenditure rate ((weight $\times$ number of visits)/days) again differed between resources (repeated measures

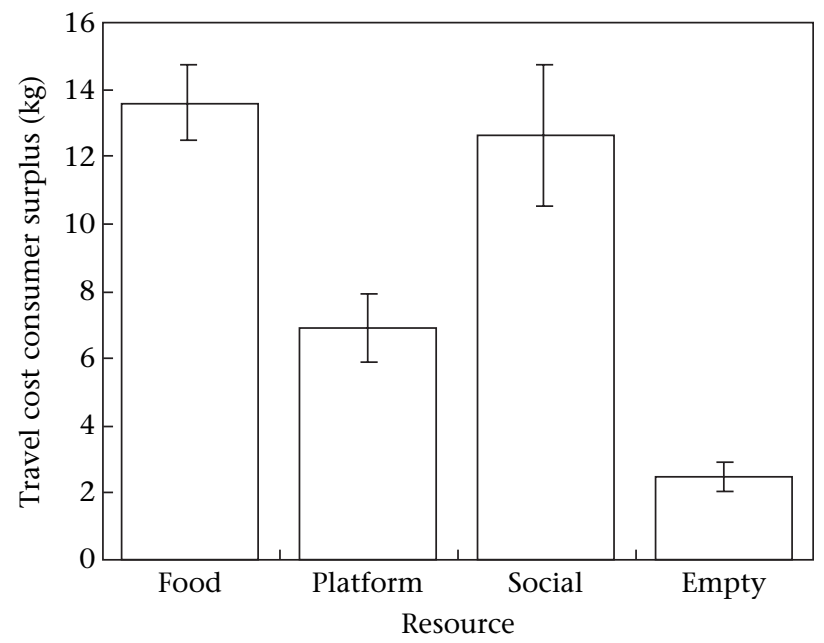

Figure 3. Mean \pm SE travel cost consumer surplus (area under the curve of weight against number of visits) for each resource. For significant differences between resources, see text.

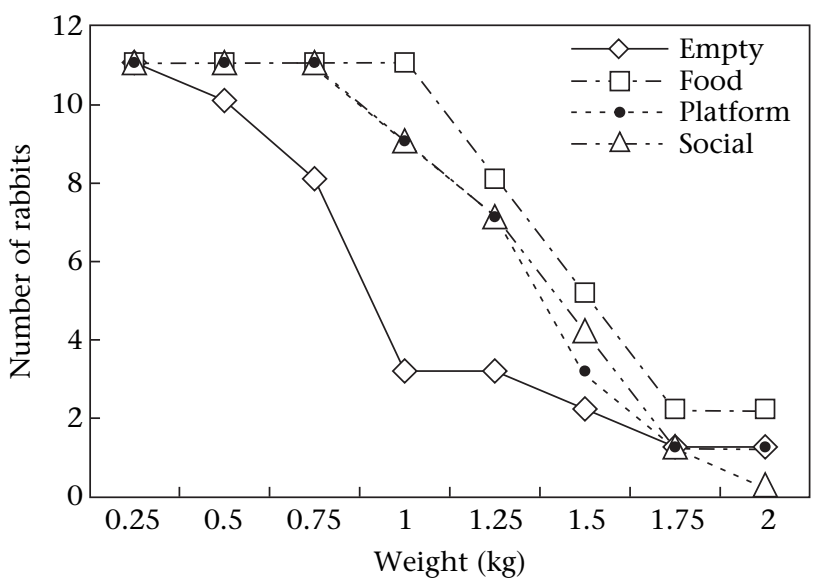

Figure 4. Number of rabbits gaining access to each resource at a given weight, against weight. For aggregate consumer surplus values, see text.

ANOVA: $F_{3,30}=13.89, P<0.001$; Fig. 6$)$, but not between individual rabbits $\left(F_{10,30}=1.19, P=0.337\right)$. LSD tests showed that the rate of expenditure on the empty cage was lower than those for the food $(P<0.001)$ and social contact $(P<0.001)$ and tended to be lower than expenditure for the platform $(P<0.1)$. The rate of expenditure for the platform was lower than those for food $(P<0.001)$ and social contact $(P<0.01)$.

\section{Behaviour in the Social and Platform Cages}

During $66.7 \%$ of the visits to the social contact cage, rabbits approached the mesh panel within $5 \mathrm{~s}$ of entering the cage, and approached within $30 \mathrm{~s}$ in $89.1 \%$ of visits. Rabbits did not approach the mesh panel at all in $6.1 \%$ of visits. The latency to approach the mesh panel after entering the cage did not differ between rabbits (repeated

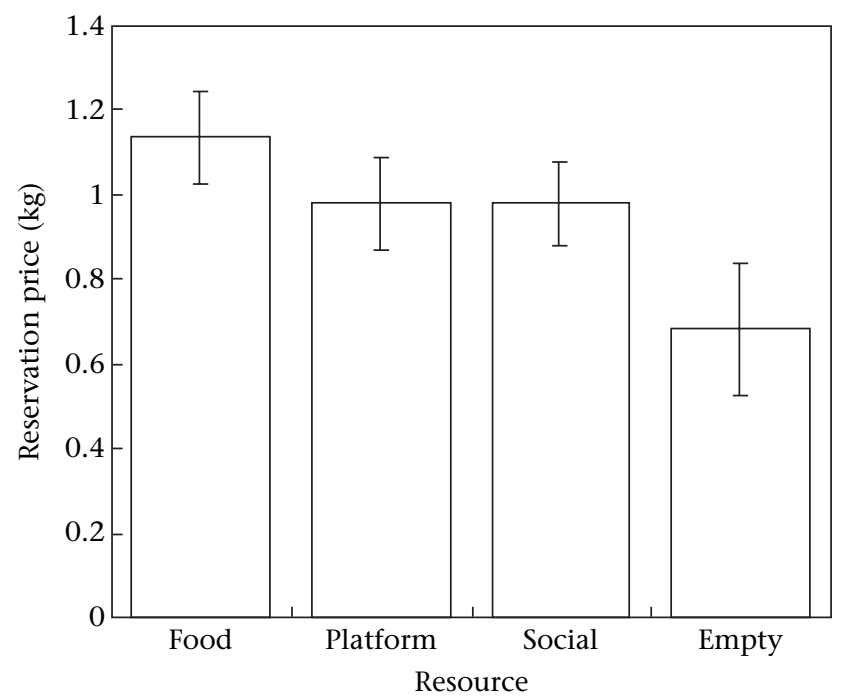

Figure 5. Mean \pm SE reservation price (maximum weight pushed) for each resource. For significant differences between resources, see text. 


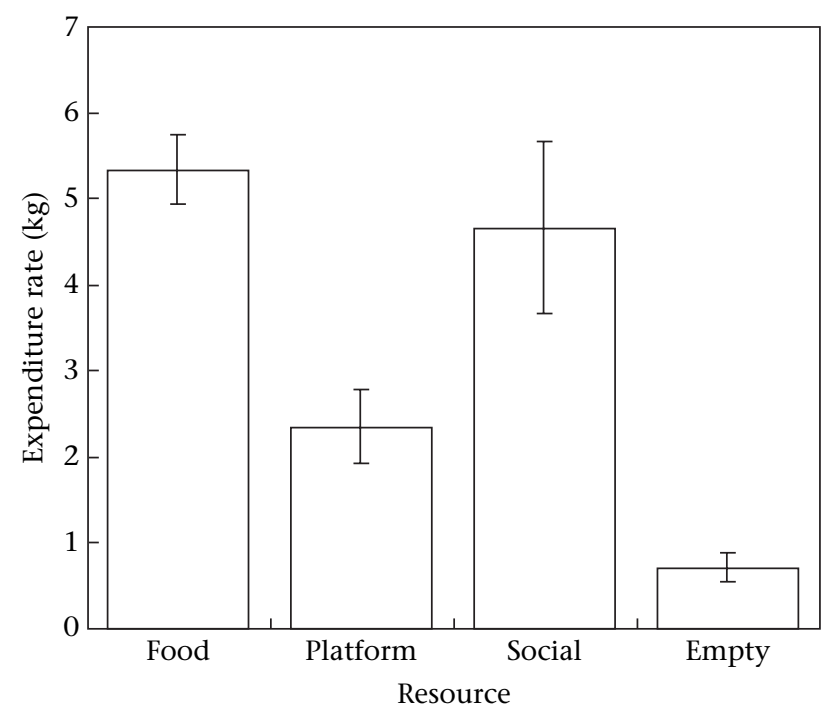

Figure 6. Mean $\pm S E$ expenditure rate ((weight $\times$ number of visits)/ day) for each resource. For significant differences between resources, see text.

measures ANOVA: $\left.F_{10,20}=1.13, P=0.389\right)$, nor between the three observation sessions $\left(F_{2,20}=1.77, P=0.196\right)$. The latency was not related to the difference in weight between the subject and stimulus rabbits (Pearson correlation: $\left.r_{9}=-0.26, P=0.45\right)$. Rabbits spent a mean $\pm \mathrm{SE}$ of $14.8 \pm 1.4 \%$ of their time at the mesh panel. The time spent here differed between rabbits (repeated measures ANOVA: $\left.F_{10,20}=2.44, P=0.043\right)$ but did not differ over the three observation sessions $\left(F_{2,20}=2.47, P=0.110\right)$. Time spent at the mesh panel was more than expected based on the available floor area (Wilcoxon test: $T=66$, $N=11, P<0.001)$. Both rabbits were at the mesh panel simultaneously $2.9 \pm 0.6 \%$ of the time. Time spent at the mesh panel was related to the difference in weight between the subject and stimulus rabbits: there was a positive correlation, suggesting that rabbits that were heavier than their stimulus rabbit spent more time at the mesh panel (Pearson correlation: $r_{9}=0.62, P=0.040$ ). There were no correlations between the difference in weight of the two rabbits and any of the economic measures (consumer surplus: $r_{9}=-0.50, P=0.12$; reservation price: $r_{9}=-0.44$, $P=0.18$; expenditure rate: $r=-0.48, P=0.14$ ). In terms of the test rabbit's behaviour at the mesh panel, the median percentage of time spent investigating the mesh panel was $99.27 \%$ (interquartile range 98.17-99.81) with the remaining $0.73 \%(0.19-1.83)$ spent standing/sitting by it. A total of 31 rears were shown by nine of the rabbits, 11 in the first observation session, eight in the second and 12 in the third. There was no correlation between the difference in weight between the subject and stimulus rabbits and rearing $\left(r_{9}=0.15, P=0.66\right)$. No other behaviours were recorded during the observations, including behaviours we had a priori judged to be aggressive (Table 1).

Time spent in the other areas of the social cage did not differ from chance expectation (Wilcoxon test: back half except close to the mesh panel: $T=22, N=11, P=0.365$; front half: $T=23, N=11, P=0.413)$. Time spent in the other areas differed between rabbits (repeated measures ANOVA: back half except close to the mesh panel: $F_{10,20}=3.19, \quad P=0.013$; front half: $F_{10,20}=7.41, \quad P<$ 0.001 ) but not observation periods (back half expect close to the mesh panel: $F_{2,20}=0.05, P=0.952$; front half: $\left.F_{2,20}=1.38, P=0.275\right)$. Although this was not systematically recorded, casual observations suggested that rabbits used the social contact cage for most of their defecation and also tended to use the corner next to the mesh panel most frequently. As door weight increased above $1 \mathrm{~kg}$, rabbits began leaving droppings in other areas such as the central area.

In the platform cages, the time spent in front of the platform did not vary with door weight, although we found differences between rabbits (repeated measures ANOVA: $F_{10,20}=4.37, P=0.002$; individual rabbit means, range $42.8-99.2 \%)$. A similar result was found for time spent on the platform: there were differences between rabbits $\left(F_{10,20}=2.57, P=0.035\right.$; individual rabbit means, range $0.2-33.5 \%$ ) but no differences between door weights. Time spent under the platform revealed no significant differences. Finally, rabbits spent longer in front of the platform (Wilcoxon test: $T=66, N=11, P<0.001$ ) and less time on $(T=5, N=11, P=0.010)$ or under it ( $T=0, N=11, P<0.001)$ than would be expected by chance (Fig. 7).

\section{DISCUSSION}

\section{Agreement/Differences between Measures of Motivation}

The different measures of resource value gave similar rankings of resource priorities (starting with the highest priority): food, social contact, platform and empty cage. However, reservation price and aggregate consumer surplus ranked social contact and the platform similarly, and almost as important as food. Expenditure rate and the travel cost consumer surplus in contrast ranked the food highest, with social contact a close, and not significantly different, second, with the platform significantly lower than these first two. Such differences are likely to stem

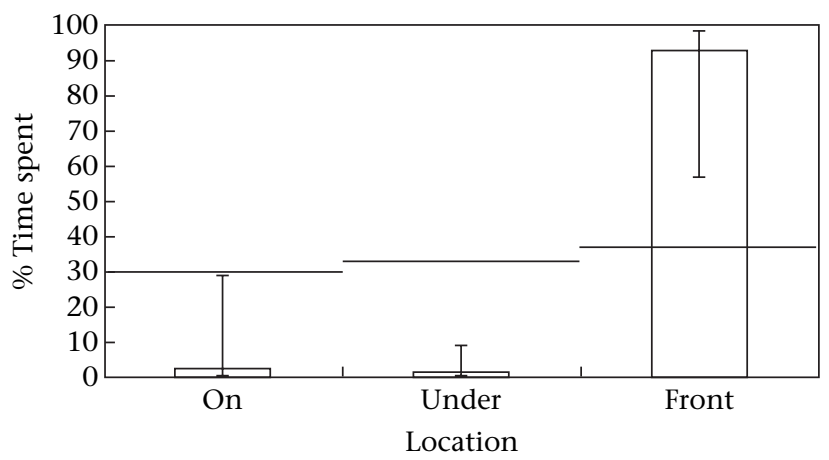

Figure 7. Median percentage of time in the platform cage spent on, under and in front of the platform. Error bars show the interquartile ranges. Horizontal lines show the expected time based on a null hypothesis of spending time in proportion to the size of each area. 
from the way the calculation of both of these latter measures uses the number of visits; the social cage tended to be visited frequently, whereas the rabbits apparently rescheduled their behaviour to a greater extent for the platform than for other resources, by making fewer but longer visits.

Furthermore, the fact that the test was terminated when each rabbit had failed to obtain food for $20 \mathrm{~h}$ also meant that on the former measures (reservation price and aggregate consumer surplus), it was impossible for food not to emerge as the highest or equal highest priority, since a rabbit could not complete a full day of responding at a higher weight for another resource and not for food without the test being terminated. Indeed, in practice, other resources were sometimes still being used when the reservation price paid for food was reached: seven of the rabbits were still visiting the social cage at the final weight and six were still visiting the platform. Despite this large constraint on the resolution of our data, we had felt that this criterion for terminating the testing was important for animal welfare reasons. However, other approaches to this problem could have been used, and are suggested below as perhaps preferable.

For all measures, the rabbits were significantly less motivated to enter the empty cage than the other resources. This indicates that the rabbits were pushing through into the other resource cages (platform, social contact and food) for the resources they contained and not solely for additional space (Sherwin \& Nicol 1997; Sherwin 2004b; Jezierski et al. 2005) or as part of territory inspection (Cowan 1977).

\section{Limited Social Contact}

Rabbits worked hard for access to limited social contact: this was not significantly different from food on any measure. These findings are important because they show that laboratory rabbits, a social species, as reviewed in the Introduction, were highly motivated to obtain even limited social contact through a wire mesh. Similarly, dairy calves, Bos taurus, were prepared to work for access to limited social contact (head only), although full social contact was more strongly defended (Holm et al. 2002). In contrast, limited social contact was found to be of little value to pigs, Sus scrofa: pigs were only a little more motivated to obtain access to caged conspecifics than a similar empty cage (Matthews \& Ladewig 1994; although the very short duration of social contact allowed here, $15 \mathrm{~s}$, may have devalued the resource in this study). Our results show that mesh panels separating neighbours could well be an enrichment and welfare benefit to single-housed laboratory rabbits.

Although no overt aggression was seen between the test and stimulus animals, rabbits that were heavier than their stimulus rabbit spent longer near the mesh panel than rabbits paired with a lighter stimulus rabbit (although the weight difference did not affect any of the measures of motivation). In addition, subjects often chose to defecate in the part of the social cage nearest to the other rabbit. These two observations could mean that the test rabbit perceived the stimulus rabbit as a threat, or as a subordinate to be dominated, rather than as a positive addition to the environment. Wild rabbits patrol and mark their territory frequently, using faecal pellets and urine, along with secretions from their chin gland (Mykytowycz 1968; Sneddon 1991) and also aggressively defend their territory against intruders (Bell 1983). Warburton \& Mason (2003) similarly found that mink, Mustela vison, worked for access to limited social contact with neighbours, despite being naturally a solitary and territorial species. Hovland et al. (2006) in their study of foxes, Vulpes vulpes, found that males would work hard for access to both male and female conspecifics; however, whereas female stimulus animals attracted affiliative responses such as tail wagging, male stimulus animals attracted threat displays. Both these studies suggest that some stimuli are not positive or enriching additions to the standard cage, even if access for them is worked for. We revisit this issue below.

\section{Platform}

Rabbits showed a rather high level of motivation to gain access to platforms. They also spent longer in the platform cage than with any of the other resources. Despite paying costs to defend access, the rabbits did not spend very much time 'using' the platform by getting on or under it. This suggests that the benefits of the platform resource cage could be had by being in proximity to the platform, perhaps for use as a 'bolt hole', in case of danger (Kolb 1991). Alternatively, the platform may have provided an opportunity for vigilance (Whary et al. 1993; Hansen \& Berthelsen 2000), but because the apparatus was built with opaque wooden sheets which the rabbits could not see over, opportunities for vigilance were limited. Observations of rabbits housed in cages with platforms (Seaman 2002) suggest that they are seen on top of the platforms more than the rabbits in the present study. It may be that a platform that improved opportunities for vigilance may have increased rabbits' motivation for access to this resource.

\section{Rescheduling of Behaviour}

As expected, in this set-up where access was costly but time spent with each resource unconstrained, the temporal patterning of behaviour changed with increasing weights: visit number declined and visit duration increased (Larkin \& McFarland 1978; Collier et al. 1990; Sherwin \& Nicol 1996; Cooper \& Mason 2000). The result of this was that total time spent with the resources remained much the same at most weights, but was lower for the unweighted and heaviest weight conditions.

In this rescheduling, there were major interactions between increasing weight and resource type. For example, the duration of each visit increased most markedly with increasing weight for the platform cage. It may be that the benefits of the other resources declined more rapidly with time once they were first obtained; for example, a hungry rabbit pays the cost to gain access to 
food, but once it has eaten its fill, food no longer has much immediate value. In contrast, if our 'bolt hole' hypothesis is correct, it could be that the opportunity to take cover quickly from a threat that could happen at any time makes a long visit to this resource valuable. The fact that the total time spent near the platform increased when the first weight was introduced and then began to decline with further weights could also be consistent with the idea of a 'bolt hole' function for the platform: when the doors were unweighted, rabbits could quickly flee to any other cage if disturbed, but once the first weight was introduced, this rapid access to cover could be had only from inside the platform cage.

With increasing cost of access to the social cage, to some extent, the number of visits made decreased and the mean duration increased; however, rabbits still made several relatively short visits to the social contact cage rather than fewer long visits. This implies that it was the frequency of the visits to the social contact cage that was important rather than the length of the visits there (Sherwin \& Nicol 1996). This may reflect the need for frequent territory inspection or defence, or instead the need for frequent positive social contact.

\section{Interaction between Resources}

The choice of resources is critical in studies such as this one, especially because resources can act as complements or substitutes to each other. If a resource only has value along with the use of another resource, its value will appear higher when both are present than when presented alone; such resources are termed complements. For example, in the absence of water, animals may not be as motivated for access to dry food pellets as they would be if water were provided. Thus in the present study, if the stimulus rabbit were perceived as a threat and the platform as a bolt hole, it could be that these two were complements. This possibility leads to some predictions which we list below.

A resource cage must also be the only place in which that resource or anything like it is available, otherwise the motivation to gain access to that resource will be reduced; resources that act on the same motivations or have similar functions are termed substitutes. For example, mink provided with a water bowl that allowed drinking but not swimming reduced their motivation for a water bath that allowed both (Mason et al. 1999). This issue is relevant to our interpretation of the use of the resource cages versus the empty cage. The presence of the empty cage helps reduce the chance that rabbits were entering the resource cages simply to obtain extra space per se (see Introduction). Rabbits' relatively low motivation for access to the empty cage should not be taken as a lack of evidence that laboratory rabbits would prefer to have extra space per se, since extra space was also available in all of the other resource cages. In fact the four resource cages and the central choice area were each about the size of a standard laboratory cage. To test the motivation of rabbits for extra space over and above the standard cage size, a separate study would need to be done with a standard cage that has access to an additional area (e.g. Sherwin \& Nicol 1997; Sherwin 2004b; Jezierski et al. 2005).

\section{Conclusions and Future Work}

As we have seen, approaches from the field of human economics can be valuable in the field of animal welfare, where animal 'consumers' are confronted with economic choices in an artificial environment. The techniques we used enabled us to get at least a preliminary quantitative ranking of resources. They also yielded information that we may well not have obtained by merely looking at animals' time budgets (e.g. Hobbs et al. 1997); for instance, rabbits spent very little time either on or under the platform, but they still worked hard simply to be in its vicinity.

We have shown that single-housed female laboratory rabbits required to pay increasing costs for access to resources show a level of motivation for limited social contact which approaches that for food. Therefore, where it is not possible to house female rabbits socially (Morton et al. 1993), the provision of this form of limited social contact may improve welfare. Furthermore, rabbits were motivated to gain access to a platform, another enrichment that could readily be added to standard laboratory cages.

This general approach, of titrating resources against costs in an artificial closed economy ecosystem, could also have value beyond welfare work. For instance, these experimental techniques could be useful for assessing the relative value of foraging substrates (and in a less simplistic manner than assessing food consumed, especially when resources have value as future resources, e.g. as hoards, that are not reflected in their current levels of consumption; Gerber et al. 2004; Healy et al. 2005); the relative value of mates (since experimentally assessing mere 'time spent near' potential mates does not always predict with whom females will actually mate; e.g. Thom et al. 2004); or for experimentally varying the circadian pattern of costs to different activities, to test ideas about the causation and optimality of daily routines in behaviour (cf. McNamara et al. 1994).

Inevitably, this work also raises future research questions. It is still unclear, for example, which measure of value best reflects the true importance of a resource for an animal's motivational state or fitness. It was also clear that the use of reservation price in combination with food raises ethical issues which, in this study, meant we stopped the trials of several animals before full information was gained on the other resources. Future work could avoid this problem in one of two ways: either reducing the price of food once its reservation price is reached, to enable the subject to feed easily while still working hard for other resources, or increasing the costs paid for each resource one at a time instead of simultaneously. This last approach would have an additional advantage: it avoids the interpretative problems induced by (1) animals abandoning resources at different rates, thus potentially increasing/decreasing the value of any remaining resources that are complements or substitutes to the abandoned 
resource; and (2) effectively reducing an animal's entire budget via increasing multiple costs at once (Kirkden \& Pajor 2006).

In our experiment, interesting new questions were also raised about the rabbits' motivation. One such is the role of the social stimulus: did it represent desired companionship, or a threat that it was important to monitor or subjugate? Several techniques could be used to answer this: observing the animals' behaviour on being allowed full access, to assess whether the behaviour was affiliative or aggressive; seeing whether the experimental removal of the stimulus rabbit from the apparatus would act to reinforce an operant response in the test rabbits; monitoring the test rabbits' state while near the stimulus rabbit (e.g. do physiological arousal and startle responses diminish, as expected if reassured by the presence of another rabbit, or increase as expected if threatened?); and looking at defecation behaviour in more detail, including the pheromonal content of pellets (faecal pellets produced at territorial latrines have stronger pheromones than those produced randomly throughout the territory; Sneddon 1991). Future work should also avoid the confound of simultaneously increasing cost and increasing familiarity, by randomizing the order of weight imposition, instead of increasing it systematically.

Finally, future work could also investigate why animals worked for the platform, to help assess environments that might increase/decrease its value, and also refine its design as an enrichment. Such experiments could see whether the value of this resource increases if it is more burrow-like and/or if it allows a better view out of the apparatus. To test our bolt hole hypothesis, it might also be interesting to see whether the value of this resource increases in environments that might be perceived as more dangerous, such as unfamiliar rooms, novel or noisy laboratory technicians, or rooms containing conspecifics that are unambiguously threatening.

\section{Acknowledgments}

This work was funded by a Ph.D. studentship awarded to S.C.S. by The Universities Federation for Animal Welfare (UFAW) Pharmaceutical Housing and Husbandry Steering Committee (PHHSC) which is a coalition of pharmaceutical companies, contract research organizations and animal welfare organizations established by the Universities Federation for Animal Welfare. SAC is supported by the Scottish Executive Environment and Rural Affairs Department.

\section{References}

Albonetti, E. M., Dessí-Fulgheri, F. \& Farabollini, F. 1990. Intrafemale agonistic interactions in the domestic rabbit (Oryctolagus cuniculus). Aggressive Behavior, 16, 77-86.

Batchelor, G. R. 1991. Group housing on floor pens and environmental enrichment in sandy lop rabbits: I. Animal Technology, 42, 109-120.

Batchelor, G. R. 1999. The laboratory rabbit. In: The UFAW Handbook on the Care and Management of Laboratory Animals (Ed. by T. Poole), pp. 395-408. Oxford: Blackwell Scientific.

Begg, D., Fischer, S. \& Dornbusch, R. 2003. Economics. London: McGraw-Hill.
Bell, D. J. 1983. Mate choice in the European rabbit. In: Mate Choice (Ed. by P. Bateson), pp. 211-223. Cambridge: Cambridge University Press.

Chu, L. R., Garner, J. P. \& Mench, J. A. 2004. A behavioral comparison of New Zealand white rabbits (Oryctolagus cuniculus) housed individually or in pairs in conventional laboratory cages. Applied Animal Behaviour Science, 85, 121-139.

Collier, G. H., Johnson, D. F., Cybulski, K. A. \& McHale, C. A. 1990. Activity patterns in rats (Rattus norvegicus) as a function of the cost of access to 4 resources. Journal of Comparative Psychology, 104, 53-65.

Cooper, J. J. \& Appleby, M. C. 1996. Demand for nest boxes in laying hens. Behavioural Processes, 36, 171-182.

Cooper, J. J. \& Mason, G. J. 2000. Increasing costs of access to resources cause re-scheduling of behaviour in American mink Mustela vison: implications for the assessment of behavioural priorities. Applied Animal Behaviour Science, 66, 135-151.

Cowan, D. P. \& Bell, D. J. 1986. Leporid social behaviour and social organisation. Mammal Review, 16, 169-179.

Cowan, P. E. 1977. Systematic patrolling and orderly behaviour of rats during recovery from deprivation. Animal Behaviour, 25, 171-184.

Dawkins, M. S. 1983. Battery hens name their price: consumer demand theory and the measurement of ethological 'needs'. Animal Behaviour, 31, 1195-1205.

Dawkins, M. S. 1990. From an animal's point of view: motivation, fitness and animal welfare. Behavioral and Brain Sciences, 13, 1-61.

European Commission. 2005. Fourth Report on the Statistics on the Number of Animals used for Experimental and Other Scientific Purposes in the Member States of the European Union. Brussels: European Commission.

Faure, J. M. \& Lagadic, H. 1994. Elasticity of demand for food and sand in laying hens subjected to variable wind-speed. Applied Animal Behaviour Science, 42, 49-59.

Fraser, D. \& Matthews, L. R. 1997. Preference and motivation testing. In: Animal Welfare (Ed. by M. C. Appleby \& B. O. Hughes), pp. 159-173. Wallingford: $C A B$ International.

Gerber, L. R., Reichman, O. J. \& Roughgarden, J. 2004. Food hoarding: future value in optimal foraging decisions. Ecological Modelling, 175, 77-85.

Gibb, J. A. 1993. Sociality, time and space in a sparse population of rabbits (Oryctolagus cuniculus). Journal of Zoology, 229, 581-607.

Gunn, D. \& Morton, D. B. 1995. Inventory of the behavior of New Zealand white rabbits in laboratory cages. Applied Animal Behaviour Science, 45, 277-292.

Gunnarsson, S., Matthews, L. R., Foster, T. M. \& Temple, W. 2000. The demand for straw and feathers as litter substrates by laying hens. Applied Animal Behaviour Science, 65, 321-330.

Hanley, N., Shogren, J. F. \& White, B. 1997. Environmental Economics in Theory and Practice. London: Macmillan.

Hansen, L. T. \& Berthelsen, H. 2000. The effect of environmental enrichment on the behaviour of caged rabbits (Oryctolagus cuniculus). Applied Animal Behaviour Science, 68, 163-178.

Healy, S. D., de Kort, S. R. \& Clayton, N. S. 2005. The hippocampus, spatial memory and food hoarding: a puzzle revisited. Trends in Ecology and Evolution, 20, 17-22.

Hobbs, B. A., Kozubal, W. \& Nebiar, F. F. 1997. Evaluation of objects for environmental enrichment of mice. Contemporary Topics in Laboratory Animal Science, 36, 69-71.

Holm, L., Jensen, M. B. \& Jeppesen, L. L. 2002. Calves' motivation for access to two different types of social contact measured by operant conditioning. Applied Animal Behaviour Science, 79, 175-194.

Home Office. 1989. Code of Practice for the Housing and Care of Animals Used in Scientific Procedures. London: HMSO. 
Home Office. 2004. Statistics of Scientific Procedures on Living Animals, Great Britain. Norwich: Home Office.

Houston, A. I. 1997. Demand curves and welfare. Animal Behaviour, 53, 983-990.

Houston, A. I. \& McNamara, J. M. 1989. The value of food: effects of open and closed economies. Animal Behaviour, 37, 546-562.

Hovland, A. L., Mason, G., Bøe, K., Steinheim, G. \& Bakken, M. 2006. Evaluation of the 'maximum price paid' as an index of motivational strength for farmed silver foxes (Vulpes vulpes). Applied Animal Behaviour Science, 100, 258-279.

Huls, W. L., Brooks, D. L. \& Beanknudsen, D. 1991. Response of adult New Zealand white rabbits to enrichment objects and paired housing. Laboratory Animal Science, 41, 609-612.

Hursh, S. R., Raslear, T. G., Shurtleff, D., Bauman, R. \& Simmons, L. 1988. A cost-benefit analysis of demand for food. Journal of the Experimental Analysis of Behavior, 50, 419-440.

Jain, M. \& Baldwin, A. L. 2003. Are laboratory animals stressed by their housing environment and are investigators aware that this stress can affect physiological data? Medical Hypotheses, 60, 284-289.

Jensen, M. B., Pedersen, L. J. \& Munksgaard, L. 2005. The effect of reward duration on demand functions for rest in dairy heifers and lying requirements as measured by demand functions. Applied Animal Behaviour Science, 90, 207-217.

Jezierski, T., Scheffler, N., Bessei, W. \& Schumacher, E. 2005. Demand functions for cage size in rabbits selectively bred for high and low activity in open-field. Applied Animal Behaviour Science, 93, 323-339.

Johnson, K. G. \& Cabanac, M. 1982. Homeostatic competition between food intake and temperature regulation in rats. Physiology and Behavior, 28, 675-679.

Kilgour, R., Foster, T. M., Temple, W., Matthews, L. R. \& Bremner, K. J. 1991. Operant technology applied to solving farm animal problems: an assessment. Applied Animal Behaviour Science, 30, 141-166.

Kirkden, R. D. \& Pajor, E. 2006. Using preference, motivation and aversion tests to ask scientific questions about animals' feelings. Applied Animal Behaviour Science, 100, 29-47.

Kirkden, R. D., Edwards, J. S. S. \& Broom, D. M. 2003. A theoretical comparison of the consumer surplus and the elasticities of demand as measures of motivational strength. Animal Behaviour, 65, 157-178.

Kolb, H. H. 1991. Use of burrows and movements of wild rabbits (Oryctolagus cuniculus) in an area of hill grazing and forestry. Journal of Applied Ecology, 28, 892-905.

Ladewig, J., Sorensen, D. B., Nielsen, P. P. \& Matthews, L. R. 2002. The quantitative measurement of motivation: generation of demand functions under open versus closed economies. Applied Animal Behaviour Science, 79, 325-331.

Larkin, S. \& McFarland, D. 1978. The cost of changing from one activity to another. Animal Behaviour, 26, 1237-1246.

Lidfors, L. 1997. Behavioural effects of environmental enrichment for individually caged rabbits. Applied Animal Behaviour Science, 52, 157-169.

McNamara, J. M., Houston, A. I. \& Lima, S. L. 1994. Foraging routines of small birds in winter: a theoretical investigation. Journal of Avian Biology, 25, 287-302.

Manser, C. E., Elliott, H., Morris, T. H. \& Broom, D. M. 1996. The use of a novel operant test to determine the strength of preference for flooring in laboratory rats. Laboratory Animals, 30, 1-6.

Mason, G., McFarland, D. \& Garner, J. 1998. A demanding task: using economic techniques to assess animal priorities. Animal Behaviour, 55, 1071-1075.

Mason, G. J., Clarebrough, C. \& Cooper, J. J. 1999. Drink or swim? Using substitutability and physiological responses to frustration to assess the importance of swimming-water for mink. In: Proceedings of the 33rd International Congress of the International Society for Applied Ethology (Ed. by K. E. Bøe, M. Bakken \& B. O. Braastad), pp. 83Lillehammer, Norway: International Society for Applied Ethology.

Mason, G. J., Cooper, J. \& Clarebrough, C. 2001. Frustrations of fur-farmed mink. Nature, 410, 35-36.

Matthews, L. R. \& Ladewig, J. 1994. Environmental requirements of pigs measured by behavioural demand functions. Animal Behaviour, 47, 713-719.

Morton, D. B., Jennings, M., Batchelor, G. R., Bell, D., Birke, L., Davies, K., Eveleigh, J. R., Gunn, D., Heath, M., Howard, B., Koder, P., Phillips, J., Poole, T., Sainsbury, A. W., Sales, G. D., Smith, D. J. A., Stauffacher, M. \& Turner, R. J. 1993. Refinements in rabbit husbandry: second report of the BVAAWF/ FRAME/RSPCA/UFAW joint working group on refinement. Laboratory Animals, 27, 301-329.

Munksgaard, L., Jensen, M. B., Pedersen, L. J., Hansen, S. W. \& Matthews, L. 2005. Quantifying behavioural priorities: effects of time constraints on behaviour of dairy cows, Bos taurus. Applied Animal Behaviour Science, 92, 3-14.

Mykytowycz, R. 1968. Territory marking by rabbits. Scientific American, 218, 116-126.

Ng, Y.-K. 1990. The case for and difficulties in using 'demand areas' to measure changes in well-being. Behavioral and Brain Sciences, 13, 30-31.

Olsson, I. A. S. \& Keeling, L. J. 2002. The push-door for measuring motivation in hens: laying hens are motivated to perch at night. Animal Welfare, 11, 11-19.

Seaman, S. C. 2002. Laboratory rabbit welfare: an investigation of the social and physical environment. Ph.D. thesis, University of Edinburgh.

Sherwin, C. M. 2004a. The influences of standard laboratory cages on rodents and the validity of research data. Animal Welfare, 13, S9-S15.

Sherwin, C. M. 2004b. The motivation of group-housed laboratory mice, Mus musculus, for additional space. Animal Behaviour, 67, 711-717.

Sherwin, C. M. \& Nicol, C. J. 1996. Reorganization of behaviour in laboratory mice, Mus musculus, with varying cost of access to resources. Animal Behaviour, 51, 1087-1093.

Sherwin, C. M. \& Nicol, C. J. 1997. Behavioural demand functions of caged laboratory mice for additional space. Animal Behaviour, $53,67-74$

Sloman, J. 1999. Economics. London: Prentice Hall.

Sneddon, I. A. 1991. Latrine use by the European rabbit (Oryctolagus cuniculus). Journal of Mammalogy, 72, 769-775.

Sorensen, D. B., Ladewig, J., Ersboll, A. K. \& Matthews, L. 2004. Using the cross point of demand functions to assess animal priorities. Animal Behaviour, 68, 949-955.

Stodart, E. \& Myers, K. 1964. A comparison of behaviour, reproduction and mortality of wild and domestic rabbits in confined populations. Wildlife Research, 9, 144-159.

Thom, M. D., Macdonald, D. W., Mason, G. J., Pedersen, V. \& Johnson, P. J. 2004. Female American mink, Mustela vison, mate multiply in a free-choice environment. Animal Behaviour, 67, 975-984.

Varian, H. R. 1993. Intermediate Microeconomics: a Modern Approach. London: W. W. Norton.

Warburton, H. \& Mason, G. 2003. Is out of sight out of mind? The effects of resource cues on motivation in mink, Mustela vison. Animal Behaviour, 65, 755-762.

Whary, M., Peper, R., Borkowski, G., Lawrence, W. \& Ferguson, F. 1993. The effects of group housing on the research use of the laboratory rabbit. Laboratory Animals, 27, 330-341.

Würbel, H. 2001. Ideal homes? Housing effects on rodent brain and behaviour. Trends in Neurosciences, 24, 207-211. 